\title{
AVALIAÇÃO DA QUALIDADE TECNOLÓGICA DO FEIJÃO DURANTE O ARMAZENAMENTO
}

\author{
Avaliation of the technological quality of the edible beans during the storage \\ Osvaldo Resende ${ }^{1}$, Paulo César Corrêa ${ }^{2}$, Lêda Rita D'Antonino Faroni², \\ Paulo Roberto Cecon ${ }^{3}$
}

\begin{abstract}
RESUMO
No presente trabalho, conduziram-se os estudos para avaliar a qualidade tecnológica dos grãos de feijão, durante quatro meses de armazenamento, em condições ambientais e na presença do inseto-praga Acanthocelides obtectus. Foram utilizados grãos de feijão com teor de água de aproximadamente 18 (\%b.s.). Para infestação do produto, foram colocados 20 insetos adultos em cada pote de vidro, que foi fechado com uma tampa telada. As análises tecnológicas foram realizadas no produto com e sem o inseto-praga, no início do experimento e a cada 28 dias, totalizando 112 dias de armazenagem. O teste de cocção foi realizado com aparelho de Mattson utilizando-se amostras previamente imersas por 12 horas. Para a determinação da absorção de água, as amostras foram submetidas à imersão em água destilada, durante um período de 12 horas, em diferentes temperaturas $\left(20,30,40\right.$ e $\left.50{ }^{\circ} \mathrm{C}\right)$. Com base nos resultados obtidos, pode-se concluir que a presença do inseto-praga causa a deterioração intensa dos grãos de feijão, resultando na redução da sua qualidade tecnológica. A temperatura de embebição aumenta a absorção de água dos grãos de feijão, sendo intensificada pela presença do inseto-praga ao longo do período de armazenamento.
\end{abstract}

Termos para indexação: Cocção, feijão, armazenamento, características tecnológicas.

\section{ABSTRACT}

The objective of this work was to evaluate the technological quality of edible bean grain during four months of storage in ambient conditions and in the presence of insect Acanthocelides obtectus. The edible beans were stored at 18.0 (\%d.b.). For the infestation of the product, were put 20 adults insects in wich recipient, than was closed with cover with screen. The technological analysis were made in product with and without the insect, in the begin of experiment and at wich 28 days, totalized 112 days of storage. The cooking test was made with Mattson apparatus utilized sample soaking for 12 hours. For determinate the water absorption, the samples were soaking in water distillated, during 12 hours in different temperatures $\left(20,30,40\right.$ and $\left.50{ }^{\circ} \mathrm{C}\right)$. For the results obtained, it was concluded that the presence of insect causes the deterioration intense of edible bean grain, result in reduction of technological quality. The temperature of soaking increase the water absorption of edible bean grain, being intensified for the presence of insect in the storage period.

Index terms: Cooking, edible bean, storage, technological characteristics.

(Recebido em 10 de março de 2006 e aprovado em 27 de março de 2007)

\section{INTRODUÇÃO}

O feijão é cultivado em quase todos os países de clima tropical e subtropical e assume enorme importância na alimentação humana, fundamentalmente devido ao seu baixo custo, e por ser um alimento relativamente balanceado, tendo pronta aceitação nos mais diferentes hábitos alimentares.

Sob o ponto de vista nutricional, o feijão é um bom alimento, pois proporciona elementos essenciais como proteínas, ferro, cálcio, vitaminas, carboidratos, fibras e lisina, que é um aminoácido essencial. Por seu alto teor de proteína (28\%) é utilizado como alternativa em substituição a carnes e outros produtos protéicos (RIOS et al., 2003).

$\mathrm{O}$ consumidor brasileiro prefere produtos recémcolhidos, que apresentam características culinárias mais satisfatórias, incluindo maiores taxas de hidratação e menor tempo de cozimento. As características de hidratação e tempo de cozimento são fatores importantes que afetam a qualidade de grãos e estão altamente correlacionados (GUEVARA, 1990). Tais características podem ser afetadas pela constituição genética do grão, associadas às condições ambientais de produção e armazenamento (COELHO, 1998).

Segundo Ibarra-Perez et al. (1996), quanto mais rápida a absorção de água, maior é a capacidade de cozimento dos grãos. Na cocção, a estrutura do grão é modificada, sendo o amido geleificado e as proteínas, desnaturadas.

A forma com que os grãos são armazenados influencia o endurecimento do tegumento e dos cotilédones

'Doutor, Professor do Centro Federal de Educação Tecnológica de Rio Verde/CEFET-RV - Rodovia Sul Goiana, Km 1 - Zona Rural - Rio Verde, Go osvresende@yahoo.com.br

2Doutores, Professores Adjunto - Departamento de Engenharia Agrícola/DEA - Universidade Federal de Viçosa/UFV - Avenida P.H Rolfs s/n - $36570-000$ Viçosa, MG - copace@ufv.br, Ifaroni@ufv.br

${ }^{3}$ Doutor, Professor Adjunto - Departamento de Informática/DPI - Universidade Federal de Viçosa/UFV - Avenida P.H Rolfs s/n - $36570-000$ - Viçosa, MG cecon@dpi.ufv.br 
e, conseqüentemente, o seu tempo de cozimento (BRACKMANN et al., 2002). O desenvolvimento do fenômeno da casca dura (hardshell) impede a reidratação dos grãos, sendo favorecido pelas condições de baixa umidade relativa na atmosfera de armazenamento, e pelo alto teor de água nos grãos. Por outro lado, o endurecimento dos cotilédones (hard-to-cook), que provoca dificuldades na sua cocção, é um fenômeno irreversível e depende principalmente das condições de armazenamento (SGARBIERI, 1987).

Segundo Rios et al. (2003), o teor de água superior ao recomendado para o armazenamento seguro é uma das principais causas da perda das suas características tecnológicas. Para Bragantini (1996), os teores de água recomendados no armazenamento, para minimizar estas perdas, deveriam estar entre 13 e 14 (\%b.u.). As condições de temperatura e umidade relativa, durante o armazenamento, podem alterar o valor nutritivo dos grãos de feijão, favorecendo a formação de compostos antinutricionais, bem como o desenvolvimento do fenômeno do endurecimento dos grãos (COELHO, 1998). Brackmann et al. (2002) verificaram que baixas temperaturas no ambiente de armazenamento resultam em menores tempos de cocção do feijão.

Segundo Rios et al. (2003), as proteínas presentes nos grãos de feijão podem sofrer alterações durante o armazenamento, podendo provocar, conseqüientemente, endurecimento do tegumento, requerendo desta forma, maior tempo para sua cocção.

Existem várias hipóteses que tentam explicar o fenômeno do endurecimento dos grãos. Uma delas seria a polimerização dos polifenóis presentes na casca, que podem migrar para os cotilédones, influenciando a sua composição (HINCKS \& STANLEY, 1987). Ainda segundo estes autores, o processo de lignificação, (oxidação e polimerização de compostos fenólicos), seja o responsável por parte da ocorrência do fenômeno de hard-to-cook, em grãos de feijão. Além dos altos níveis de carboidratos, proteínas e minerais, o feijão apresenta compostos antinutricionais como os polifenóis (taninos) e o ácido fítico, que podem estar associados ao fenômeno hard-tocook, aumentando o tempo de cocção e diminuindo sua palatabilidade (COELHO, 1998).

Para Udaeta \& Lajolo (1997), os compostos fenólicos também estão relacionados com o endurecimento dos grãos na pós-colheita, ocorrendo um aumento dos seus níveis e no tempo de cocção, após 3 e 6 meses de armazenamento, nas condições de $30^{\circ} \mathrm{C}$ de temperatura e $70 \%$ de umidade relativa.

Segundo Sartori (1982), os compostos fenólicos também estão correlacionados com o escurecimento de grãos quando na presença de oxigênio, fato ocasionado por oxidações enzimáticas ocorridas no tegumento. Os teores de água, temperatura e o período de armazenamento também influenciam no escurecimento do tegumento, conforme diversos autores (BURR et al., 1968; IADEROZA et al., 1989; SARTORI, 1982).

Além disso, o armazenamento do feijão é normalmente realizado em condições inadequadas para a preservação de suas qualidades, sem o monitoramento do teor de água, podendo ocorrer infestações de pragas, que causam perdas qualitativas e quantitativas, reduzindo os valores nutritivos e comerciais do produto.

Dentre as espécies de pragas encontradas em grãos armazenados e seus subprodutos, destacam-se os insetos, como um importante agente responsável por perdas e depreciação dos produtos, no período pós-colheita. $\mathrm{O}$ ataque de insetos pode causar redução da massa e/ou do volume dos grãos, aquecimento do produto durante o armazenamento, disseminação de microrganismos, favorecendo a infestação por patógenos, redução do poder germinativo e do vigor em sementes, além de contribuir para o aumento do custo de produção pela necessidade da prática da controle (FARONI et al., 1995).

Assim, objetivou-se com este trabalho, avaliar a qualidade tecnológica dos grãos de feijão, por meio das análises do tempo de cocção, absorção de água em diferentes temperaturas, durante quatro meses de armazenamento, em condições ambientais e na presença do inseto-praga $A$. obtectus.

\section{MATERIAL E MÉTODOS}

O presente trabalho desenvolveu-se no Laboratório de Propriedades Físicas e Qualidade de Produtos Agrícolas pertencente ao Centro Nacional de Treinamento em Armazenagem (CENTREINAR), localizado na Universidade Federal de Viçosa, Viçosa - MG.

Para a condução do experimento, foram utilizados grãos de feijão do grupo vermelho, cultivar vulgarmente denominado "vermelhinho", da safra de inverno do ano de 2004 no município de Cajuri-MG e colhidos manualmente, com teor de água de, aproximadamente, $25,0 \%$ (b.s.) e secos até o teor de água de $18,0 \%$ (b.s.). $\mathrm{O}$ produto foi submetido ao expurgo com fosfina e acondicionado em frascos de vidro, com capacidade para $1,5 \mathrm{~kg}$, durante um período de 112 dias. Os frascos foram mantidos sob condições controladas de temperatura $\left(26 \pm 3{ }^{\circ} \mathrm{C}\right)$ e umidade relativa do $\operatorname{ar}(55 \pm 10 \%)$, em ambiente de laboratório.

Para infestação do produto, foram colocados 20 insetos adultos da espécie A. obtectus em cada frasco, 
que foi fechado com uma tampa telada para garantir a entrada de oxigênio e a sobrevivência dos insetos.

Para avaliação tecnológica do feijão, na presença e na ausência do inseto-praga, foram realizadas as análises de classificação do produto, grau de infestação, teor de água, tempo de cocção e absorção de água, a cada 28 dias até 112 dias de armazenamento.

\section{Classificação do produto}

A classificação do produto foi realizada por técnico especializado do Ministério da Agricultura, de acordo com a norma oficial da Portaria № 161 de 24 de julho de 1987 (BRASIL, 1987). Esta norma classifica o feijão em 5 tipos, de acordo com a qualidade do produto, expresso por números de 1 a 5 e definidos, de acordo com os limites máximos de tolerância de defeitos.

\section{Grau de infestação}

O grau de infestação do produto foi determinado segundo a metodologia descrita nas Regras para Análise de Sementes (BRASIL, 1992). Foram utilizadas duas repetições contendo, cada uma, 100 grãos. Para facilitar o corte, os grãos de feijão foram imersos em água, durante um período de 12 horas. O feijão foi considerado infestado, quando apresentava no seu interior qualquer uma das fases do inseto-praga: ovo, larva, pupa e inseto adulto, e também, pela presença do orifício de saída do inseto. $\mathrm{O}$ resultado foi expresso em porcentagem de grãos infestados.

\section{Teor de água}

Os teores de água do produto foram determinados pelo método da estufa, $105 \pm 1^{\circ} \mathrm{C}$, durante 24 horas, em três repetições (BRASIL, 1992).

\section{Tempo de cocção}

Para a determinação do tempo de cocção, utilizaramse amostras previamente imersas, por 12 horas. O teste foi realizado com aparelho de Mattson, de acordo com a metodologia descrita por Tomé et al. (2001). O aparelho cozedor possui 25 hastes com $21,6 \mathrm{~cm}$ de comprimento e massa de 82,0 gramas cada um. Na extremidade, a haste apresenta uma ponta afunilada com $0,2 \mathrm{~cm}$ de diâmetro e comprimento de $0,9 \mathrm{~cm}$, que foi apoiada, perpendicularmente, sobre cada grão. O aparelho foi colocado no interior de um recipiente metálico com um litro de água em estado de ebulição, mantido a volume constante. Os grãos foram considerados cozidos quando a haste os atravessou, sendo o tempo de cocção da amostra registrado, quando a 13 a haste penetrou o grão.

\section{Absorção de água}

Para a estimação da absorção de água, as amostras foram submetidas à imersão em água destilada, durante um período de 12 horas. Foram analisadas diferentes temperaturas $\left(20,30,40\right.$ e $\left.50{ }^{\circ} \mathrm{C}\right)$, durante a embebição do produto, de acordo com Abu-Ghnnam \& Mckenna (1997). Foi utilizado um becker (capacidade de $100 \mathrm{~mL}$ ), contendo $80 \mathrm{~mL}$ de água destilada juntamente com $20 \mathrm{~g}$ de produto, perfazendo uma relação em massa de 4/1. Após o período de imersão, as amostras foram retiradas dos beckers e colocadas sobre papel de filtro para escorrimento da água superficial, durante dois minutos. A absorção de água representa a quantidade de água absorvida pelo produto em função da sua matéria seca, sendo determinada por meio da seguinte expressão:

$$
\mathrm{Ab}=\frac{\mathrm{M}_{\mathrm{e}}-\mathrm{M}_{\mathrm{s}}}{\mathrm{M}_{\mathrm{s}}}
$$

em que:

Ab: absorção de água do produto, decimal;

$\mathrm{M}_{\mathrm{e}}$ : massa depois da embebição, $\mathrm{kg}$;

$\mathrm{M}_{\mathrm{s}}$ : massa da matéria seca do produto, $\mathrm{kg}$.

A matéria seca do feijão foi determinada em estufa, $105 \pm 1{ }^{\circ} \mathrm{C}$, durante 24 horas, em três repetições (BRASIL, 1992).

\section{Análises estatísticas}

O experimento foi montado segundo o esquema em parcela subdividida, tendo nas parcelas os níveis de infestação (presença e ausência do inseto-praga) e nas sub-parcelas o tempo de armazenamento, no delineamento inteiramente casualizado com três repetições. Para a absorção de água, acrescentaram-se nas parcelas as temperaturas de embebição $\left(20,30,40\right.$ e $\left.50^{\circ} \mathrm{C}\right)$. Os dados foram analisados por meio de análise de variância e regressão. Para o fator qualitativo as médias foram comparadas utilizando-se o teste de Tukey, adotando-se o nível de $5 \%$ de probabilidade. Para o fator quantitativo, os modelos foram selecionados com base na significância da equação, pelo teste $\mathrm{F}$, na significância dos coeficientes de regressão, utilizando-se o teste de " $\mathrm{t}$ " adotando-se o nível de $5 \%$ de probabilidade, no coeficiente de determinação e no conhecimento do fenômeno biológico.

\section{RESULTADOS E DISCUSSÃO}

Para todas as variáveis analisadas, verificou-se que as interações entre os fatores testados foram significativas. Desta forma, promoveram-se os desdobramentos das 
interações em função dos fatores de maior interesse para o trabalho.

\section{Classificação do produto}

$\mathrm{Na}$ Tabela 1, está apresentado o resultado da classificação do feijão para cada tratamento, ao longo do armazenamento.

Tabela 1 - Classificação do feijão, com e sem a presença do inseto-praga, ao longo do armazenamento.

\begin{tabular}{ccc}
\hline \multirow{2}{*}{$\begin{array}{c}\text { Período de } \\
\text { armazenamento } \\
\text { (dias) }\end{array}$} & \multicolumn{2}{c}{ Tipo final } \\
\cline { 2 - 3 } 28 & Sem insetos & Com insetos \\
\hline 0 & 1 & 1 \\
56 & 1 & 1 \\
84 & 1 & $\begin{array}{l}\text { abaixo do padrão } \\
\text { - excesso de } \\
\text { carunchos } \\
\text { abaixo do padrão } \\
\text { - excesso de } \\
\text { carunchos }\end{array}$ \\
\hline
\end{tabular}

De acordo com a Tabela 1, verifica-se que o feijão enquadrou-se, inicialmente, como Tipo 1. Estas características permaneceram, ao longo do armazenamento, no produto sem a infestação por insetos. O feijão com a presença do inseto-praga manteve as características iniciais até os 56 dias de armazenamento. Aos 84 e 112 dias depois de armazenado, o produto foi considerado abaixo do padrão, devido, essencialmente, à elevada infestação dos grãos.

\section{Grau de infestação}

Na Tabela 2, estão apresentadas as médias do grau de infestação dos grãos de feijão ao longo do período de armazenamento.
Observa-se na Tabela 2 que, a partir dos 84 dias de armazenamento, a população do inseto-praga, em comparação à testemunha, aumentou significativamente, chegando, ao final do período, com 91,67\% dos grãos infestados.

Na Tabela 3 estão apresentadas as equações ajustadas para o grau de infestação, em função do período de armazenamento. Verifica-se que, para os grãos sem insetos, ocorreram diversos valores nulos na avaliação do grau de infestação, sendo indicado para sua representação a própria média dos valores observados. A infestação identificada na testemunha foi, possivelmente, decorrente do ataque de insetos antes da execução do expurgo, com o produto ainda na lavoura.

De acordo com a Tabela 3, observa-se que a infestação dos grãos de feijão aumentou, exponencialmente, ao longo do armazenamento, indicando que houve uma elevada taxa de crescimento dos insetos.

\section{Teor de água}

Na Tabela 4 estão evidenciados os valores médios do teor de água do feijão, com e sem a infestação do inseto-praga, ao longo do período de armazenamento.

Observa-se na Tabela 4 que o teor de água dos grãos permaneceu em equilíbrio com as condições do ar, no interior dos frascos (temperatura e umidade relativa), durante o armazenamento. Verifica-se que os valores do teor de água foram, significativamente, maiores para o feijão na presença do inseto-praga aos 84 e 112 dias de armazenamento, de acordo com o teste de Tukey, a $5 \%$ de probabilidade. Este fato devese à evolução da população do inseto-praga, a partir dos 84 dias de armazenamento, causada principalmente, pela elevação da taxa respiratória dos grãos e insetos.

$\mathrm{Na}$ Tabela 5 estão apresentadas as equações ajustadas para o teor de água, em função do período de armazenamento para os tratamentos analisados.

Tabela 2 - Valores médios do grau de infestação (\%) dos grãos de feijão, na presença e ausência do inseto-praga, durante o armazenamento.

\begin{tabular}{cccccc}
\hline \multirow{2}{*}{ Fatores } & \multicolumn{5}{c}{ Período de armazenamento (dias) } \\
\cline { 2 - 5 } & 0 & 28 & 56 & 84 & 112 \\
\hline Sem insetos & $0,00 \mathrm{a}$ & $0,67 \mathrm{a}$ & $0,00 \mathrm{a}$ & $0,00 \mathrm{~b}$ & $0,33 \mathrm{~b}$ \\
Com insetos & $0,00 \mathrm{a}$ & $1,00 \mathrm{a}$ & $2,00 \mathrm{a}$ & $22,67 \mathrm{a}$ & $91,67 \mathrm{a}$ \\
\hline
\end{tabular}

Médias seguidas pela mesma letra na coluna não diferem entre si ao nível de 5\% de probabilidade, pelo teste Tukey. 
Tabela 3 - Equação ajustada para o grau de infestação (GI, \%), em função do período de armazenamento (t, dias) para o feijão infestado por insetos, com o respectivo coeficiente de determinação, e média geral para o produto sem insetos.

\begin{tabular}{ccc}
\hline Tratamento & Modelo & $\mathrm{r}^{2}(\mathrm{decimal})$ \\
\hline Sem insetos & $\mathrm{GI}=0,2$ & - \\
Com insetos & $\mathrm{GI}=0,265^{++} \cdot \mathrm{e}^{\left(0,052^{++} \cdot \mathrm{t}\right)}$ & $0,998^{*}$ \\
\hline
\end{tabular}

\footnotetext{
${ }^{++}$Significativo a $5 \%$ pelo teste $\mathrm{t}$.
}

* Significativo a $5 \%$ pelo teste $\mathrm{F}$.

Tabela 4 - Valores médios do teor de água do feijão (\%b.s.), na presença e ausência do inseto-praga, ao longo do período de armazenamento.

\begin{tabular}{cccccc}
\hline \multirow{2}{*}{ Fatores } & \multicolumn{6}{c}{ Período de armazenamento (dias) } \\
\cline { 2 - 6 } & 0 & 28 & 56 & 84 & 112 \\
\hline Sem insetos & $18,72 \mathrm{a}$ & $18,23 \mathrm{a}$ & $17,80 \mathrm{a}$ & $15,91 \mathrm{~b}$ & $15,31 \mathrm{~b}$ \\
Com insetos & $18,71 \mathrm{a}$ & $18,54 \mathrm{a}$ & $18,00 \mathrm{a}$ & $17,70 \mathrm{a}$ & $26,55 \mathrm{a}$ \\
\hline
\end{tabular}

Médias seguidas pela mesma letra na coluna não diferem entre si ao nível de 5\% de probabilidade pelo teste Tukey.

Tabela 5 - Equações de regressão ajustadas para o teor de água (U*, \%b.s.), em função do período de armazenamento (t, dias), para os respectivos tratamentos e coeficientes de determinação.

\begin{tabular}{ccc}
\hline Tratamento & Modelo & $\mathrm{r}^{2}($ decimal $)$ \\
\hline Sem insetos & $\mathrm{U}^{*}=19,02-0,0326^{++} \cdot \mathrm{t}$ & $0,932^{*}$ \\
Com insetos & $\mathrm{U}^{*}=19,54-0,1337 \cdot \mathrm{t}+0,0017 \cdot \mathrm{t}^{2}$ & 0,821 \\
\hline
\end{tabular}

${ }^{++}$Significativo a $1 \%$ pelo teste $\mathrm{t}$.

* Significativo a $5 \%$ pelo teste $\mathrm{F}$.

Analisando a Tabela 5, observa-se que o teor de água do feijão na ausência do inseto-praga diminuiu, aproximadamente 0,03 (\%b.s.) em cada dia de armazenamento. Este fato deve-se à variação das condições ambientais sob as quais foi realizado o experimento (temperatura de $26 \pm 3{ }^{\circ} \mathrm{C}$ e umidade relativa do ar $55 \pm 10 \%$ ), que apresentaram tendência de aumento da temperatura e redução da umidade relativa, ao longo do período de armazenamento. O teor de água do feijão, na presença do inseto-praga, foi influenciado pelas condições ambientais, causando, inicialmente, redução dos seus valores, e depois da intensificação da infestação dos grãos, aumentou quadraticamente, ao longo do tempo de armazenamento.

\section{Tempo de cocção}

Na Tabela 6 estão apresentadas as médias para cada tratamento, ao longo das épocas de armazenamento. Notase que houve um aumento gradativo no tempo de cocção à medida que os grãos permanecem armazenados, com exceção para o feijão aos 112 dias de armazenagem, e pela infestação generalizada dos grãos, o tempo de cocção foi significativamente inferior à testemunha. Estes resultados eram esperados, pois os grãos infestados apresentam danificações no tegumento os quais facilitam a cocção.

Na Tabela 7 estão apresentados os modelos para o desdobramento da interação entre os tratamentos analisados (com e sem infestação), ao longo das épocas de armazenamento.

Observa-se na Tabela 7, que os valores do tempo de cocção (TC) aumentaram significativamente, ao longo do período de armazenamento (t), como observado por diversos pesquisadores (BRACKMANN et al., 2002; RESENDE et al., 2004; SHIGA et al., 2004). O modelo linear representa satisfatoriamente os valores experimentais, sendo significativo a $5 \%$ de probabilidade pelo teste " $t$ ", e apresentando elevado valor do coeficiente de determinação $\left(\mathrm{r}^{2}\right)$. 


\section{Absorção de água}

Para a variável em estudo, a interação entre os fatores analisados (infestação do produto, período de armazenamento e temperatura de embebição) foi significativa. Assim, procedeu-se ao desdobramento da absorção de água em função da temperatura e do período de armazenamento.

$\mathrm{Na}$ Tabela 8, são apresentadas as equações de regressão ajustadas para os dados de absorção de água, em função da temperatura de embebição e do período de armazenamento. Pela análise dos resultados, observa-se que as equações ajustadas apresentaram elevados valores do coeficiente de determinação $\left(\mathrm{r}^{2}\right)$, mostrando-se satisfatórias na descrição do fator em estudo e incorporando o efeito da temperatura e do período de armazenamento, na absorção de água do feijão.

Na Figura 1 está apresentada à superfície de resposta, ajustada de acordo com a equação anterior, para

Tabela 6 - Valores médios do tempo de cocção (TC, minutos) dos grãos de feijão, com e sem a infestação do insetopraga, ao longo do período de armazenamento.

\begin{tabular}{cccccc}
\hline \multirow{2}{*}{ Fatores } & \multicolumn{5}{c}{ Período de armazenamento (dias) } \\
\cline { 2 - 6 } & 0 & 28 & 56 & 84 & 112 \\
\hline Sem insetos & $27,27 \mathrm{a}$ & $32,75 \mathrm{a}$ & $36,31 \mathrm{a}$ & $45,27 \mathrm{a}$ & $56,14 \mathrm{a}$ \\
Com insetos & $28,05 \mathrm{a}$ & $29,52 \mathrm{a}$ & $37,43 \mathrm{a}$ & $41,87 \mathrm{a}$ & $40,15 \mathrm{~b}$ \\
\hline
\end{tabular}

Médias seguidas pela mesma letra na coluna não diferem entre si ao nível de 5\% de probabilidade pelo teste Tukey.

Tabela 7 - Modelos matemáticos para a representação do tempo de cocção (TC, minutos) do feijão, ao longo do período de armazenamento (t, dias).

\begin{tabular}{ccc}
\hline Tratamento & Modelo & $\mathrm{r}^{2}($ decimal $)$ \\
\hline Sem insetos & $\mathrm{TC}=25,497+0,251^{++} \cdot \mathrm{t}$ & $0,958^{*}$ \\
Com insetos & $\mathrm{TC}=28,093+0,131^{+} \cdot \mathrm{t}$ & $0,850^{*}$
\end{tabular}

${ }^{+}$Significativo a $5 \%$ pelo teste $\mathrm{t} ;{ }^{++}$Significativo a $1 \%$ pelo teste $\mathrm{t}$;

* Significativo a $5 \%$ pelo teste $\mathrm{F}$.

Tabela 8 - Equações de regressão ajustadas para absorção de água (Ab), em função da temperatura de embebição (T) e do período de armazenamento $(\mathrm{P})$.

\begin{tabular}{llc}
\hline Tratamento & \multicolumn{1}{c}{ Modelo } & $\mathrm{r}^{2}($ decimal $)$ \\
\hline \multirow{2}{*}{ Sem insetos } & $\mathrm{Ab}=1,4424-(0,0005 \cdot \mathrm{P})-(0,0048 \cdot \mathrm{T})+\left(0,000001 \cdot \mathrm{P}^{2}\right)+$ & $0,949^{*}$ \\
& $\left(0,00001 \cdot \mathrm{T}^{2}\right)+(0,000001 \cdot \mathrm{P} \cdot \mathrm{T})$ & \\
Com insetos & $\mathrm{Ab}=1,4266+(0,0006 \cdot \mathrm{P})-(0,0055 \cdot \mathrm{T})+\left(0,000001 \cdot \mathrm{P}^{2}\right)+$ & $0,684^{*}$ \\
& $\left(0,0002 \cdot \mathrm{T}^{2}\right)-(0,0001 \cdot \mathrm{P} \cdot \mathrm{T})$ & \\
\hline
\end{tabular}

* Significativo a $5 \%$ pelo teste $\mathrm{F}$.

em que:

Ab: absorção de água, (decimal);

T: temperatura de embebição, ${ }^{\circ} \mathrm{C}$;

P: período de armazenamento, dias. 
a absorção de água do feijão, em função da temperatura de embebição e do tempo de armazenamento, sem a presença do inseto-praga. Observa-se que os valores da absorção de água aumentam com a elevação da temperatura de embebição e do tempo de armazenamento. Resultados semelhantes foram observados por Bhattacharya (1995), que verificou o aumento da hidratação das sementes de milho, com a elevação da temperatura de embebição de 30 para $100{ }^{\circ} \mathrm{C}$.

Na Figura 2 está apresentada a superfície de resposta para a absorção de água do feijão, com a presença do A. obtectus, em função da temperatura de embebição e do tempo de armazenamento. Verifica-se que a absorção de água dos grãos de feijão foi influenciada pela danificação causada pelos insetos, ao longo do período de armazenamento. A presença do inseto-praga promoveu aumento acentuado nos valores da absorção de água, principalmente aos 112 dias de armazenamento, onde se observa a infestação generalizada do produto, com a conseqüente danificação do tegumento, para todas as temperaturas de embebição analisadas.

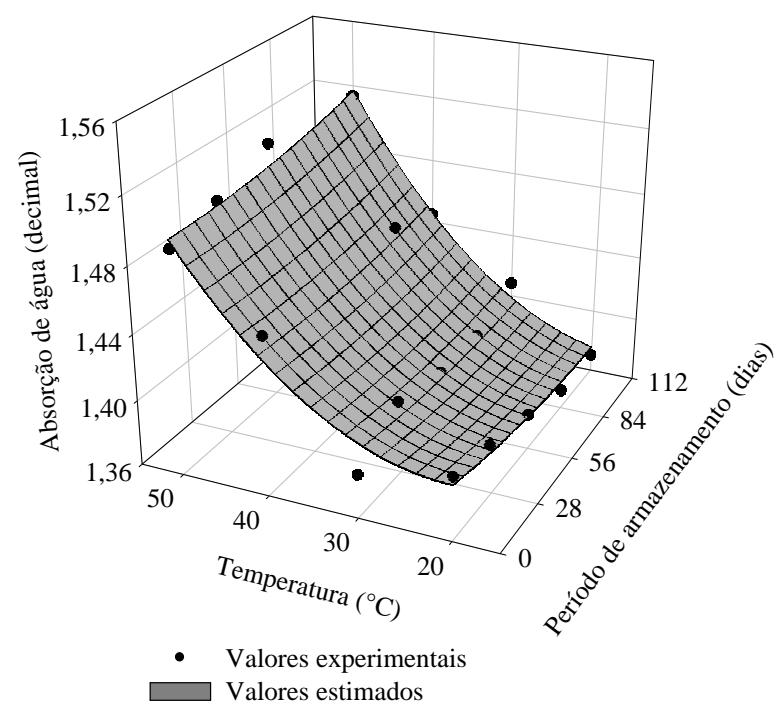

Figura 1 - Valores experimentais e estimados da absorção de água para o feijão (decimal), em função da temperatura de embebição e do tempo de armazenamento, sem a presença do inseto-praga.

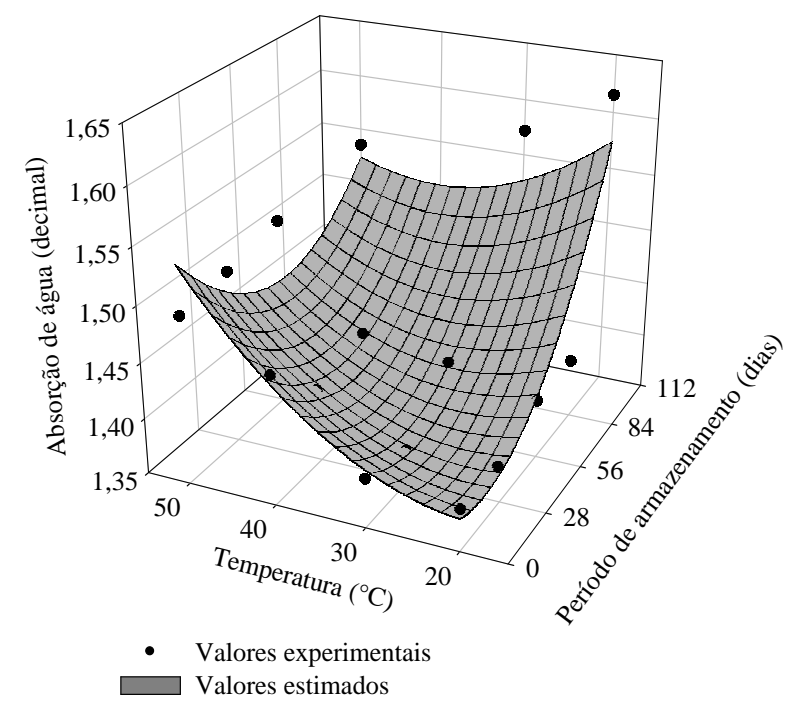

Figura 2 - Valores experimentais e estimados da absorção de água para o feijão (decimal), com a infestação do insetopraga, em função da temperatura de embebição e do tempo de armazenamento.

\section{CONCLUSÕES}

A presença do inseto-praga causa a deterioração intensa dos grãos de feijão, resultando na redução da sua qualidade tecnológica. A temperatura de embebição aumenta a absorção de água dos grãos de feijão, sendo intensificada pela presença do inseto-praga, ao longo do período de armazenamento.

\section{AGRADECIMENTOS}

À CAPES, ao CNPq e a FAPEMIG pelo apoio financeiro indispensável na execução do presente trabalho.

\section{REFERÊNCIAS BIBLIOGRÁFICAS}

ABU-GHANNAM, N.; MCKENNA, B. The application of Peleg's equation to model water absorption during the soaking of red kidney beans (Phaseolus vulgaris L.). Journal of Food Engineering, Essex, v. 32, p. 391-401, 1997.

BHATTACHARYA, S. Kinetics of hydration of raw and roasted corn semolina. Journal of Food Engineering, Essex, v. 25, p. 21-30, 1995. 
BRACKMANN, A.; NEUWALD, D. A.; RIBEIRO, N. D.; MEDEIROS, E. A. A. Condição de armazenamento de feijão (Phaseolus vulgaris L.) do grupo carioca "FT Bonito". Revista Brasileira de Armazenamento, Viçosa, v. 27, n. 1, p. 16-20, 2002.

BRAGANTINI, C. Produção de sementes. In: ARAÚJO, R. S.; AGUSTIN RAVA, C.; STONE, L. F.; ZIMMERMANN, M. J. O. Cultura do feijoeiro comum no Brasil. Piracicaba: Potafos, 1996. cap. 4, p. 639-667.

BRASIL. Ministério da Agricultura e Reforma Agrária. Secretaria Nacional de Defesa Agropecuária. Regras para análise de sementes. Brasília, DF, 1992. 365 p.

BRASIL. Ministério da Agricultura, Pecuária e Abastecimento. Portaria n. 161, de 24 de julho de 1987. Normas e padrões, a ser observada na padronização, classificação, embalagem e apresentação do feijão. 1987. Disponível em: <http://www.agricultura.gov.br>. Acesso em: 8 abr. 2004.

BURR, K. H.; KON, S.; MORRIS, H. J. Cooking rates of dry beans as influenced by moisture content, temperature and time of storage. Food Technology, Chicago, v. 22, p. 336338, 1968.

COELHO, C. M. M. Caracterização genética de dois acessos de feijoeiro (Phaseolus vulgaris $\mathrm{L}$.) com ênfase na qualidade pós-colheita. 1998. 105 f. Dissertação (Mestrado em Ciências) - Escola Superior de Agricultura de Luiz de Queiroz, Piracicaba, 1998.

FARONI, L. R. A.; SILVA, J. F.; SILVA, F. A. P. Pragas e métodos de controle. In: SILVA, J. S. (Ed.). Préprocessamento de produtos agrícolas. Juiz de Fora: Instituto Maria, 1995. p. 363-392.

GUEVARA, L. L. V. Avaliação sensorial e inativação de lipoxigenase em feijão (Phaseolus vulgaris L.) armazenados em condições ambientais. 1990. $132 \mathrm{f}$. Dissertação (Mestrado em Ciências dos Alimentos) - Escola Superior de Agricultura de Lavras, Lavras, 1990.

HINCKS, M. J.; STANLEY, D. W. Lignification: evidence for a role in hard-to-cook beans. Journal of Food Biochemistry, [S.1.], v. 11, n. 1, p. 41-58, 1987.

IADEROZA, M.; SALES, A. N.; BALDINI, V. L. S.; SARTORI, M. L.; FERREIRA, V. L. P. Atividade de polifenoloxidase e alterações da cor e dos teores de taninos condensados em novas cultivares de feijão (Phaseolus vulgaris L.) durante o armazenamento. Coletânea do Instituto de Tecnologia de Alimentos, Campinas, n. 19, p. 154-164, 1989.

IBARRA-PÉREZ, F. J.; CASTILHO-ROSALES, A.; CUELLAR-EVENOR, I. Treshing effect on cooking time in commercial beans cultivars from the semiarid highlands of Mexico. Bean Improvement Cooperative, Cali, v. 39, p. 264265, Feb. 1996.

RESENDE, O.; BOREM, F. M.; GRIS, C. F.; PEREIRA, R. G. F. A. Avaliação da qualidade tecnológica de grãos de feijão (Phaseolus vulgaris L.) armazenados na presença de equipamento redutor de inóculo. Revista Brasileira de Armazenamento, Viçosa, v. 29, n. 2, p. 143-151, 2004.

RIOS, A. O.; ABREU, C. M. P.; CORRÊA, A. D. Efeito da estocagem e das condições de colheita sobre algumas propriedades físicas, químicas e nutricionais de três cultivares de feijão (Phaseolus vulgaris L.). Ciência e Tecnologia de Alimentos, Campinas, v. 23, p. 39-45, 2003.

SARTORI, M. R. Technological quality of dry beans (Phaseolus vulgaris L.) stored under nitrogen. 1982. Thesis (Ph.D.) - Kansas State University, Manhattan, 1982.

SGARBIERI, V. C. Alimentação e nutrição: fator de saúde e desenvolvimento. Campinas: Unicamp, 1987. 387 p.

SHIGA, T. M.; LAJOLO, F. M.; FILISETTI, T. M. C. C. Changes in the cell wall polysaccharides during storage and hardening of beans. Food Chemistry, London, v. 84, p. 53-64, 2004

TOMÉ, P. H. F.; SANTOS, J. P.; CABRAL, L. C.; CHANDRA, P. K.; GONÇALVES, R. A. Uso da atmosfera controlada pelo $\mathrm{CO}_{2}$ e $\mathrm{N}_{2}$ na preservação das qualidades tecnológicas do feijão (Phaseolus vulgaris L.) durante o armazenamento. Revista Brasileira de Armazenamento, Viçosa, v. 25, n. 2, p. 16-22, 2000.

UDAETA, J. E. M.; LAJOLO, F. M. Compostos fenólicos e sua relação com o endurecimento de feijões (Phaseolus vulgaris $\mathrm{L}$.) em diferentes condições de armazenamento. In: SIMPÓSIO LATINO AMERICANO DE CIÊNCIA DE ALIMENTOS, 2., 1997, Campinas. Anais... Campinas: FEA/ Unicamp, 1997. 